\title{
Rural Nursing During the COVID-19 Pandemic: A Snapshot of Nurses' Experiences from Aotearoa New Zealand
}

\author{
Jean Ross* (D), Samuel Mann (D) and Griffin Leonard \\ College of Health, Otago Polytechnic, Dunedin, New Zealand
}

\begin{abstract}
Introduction: The aim of this article was to collect and analyseif/how the COVID-19 pandemic had affected the practice of rural nurses'from Aotearoa, New Zealand.

Methods: This qualitative study involved nine rural nurse paticipants from New Zealand. All participants engaged with an individual zoom interview, during the pandemic lockdown. The interviews were conducted and audio recorded with the first author, guided by a set number of questions. The interviews were edited and produced as a podcast before being played on a local radio station in New Zealand.Thematic analysis was used to analyse theedited recorded podcast interviews.
\end{abstract}

\begin{abstract}
Results: During COVID-19 rural nurses' became welfare providers and community educators, they upskilled their practice and worked at a distance. They were effective communicators and collaborators with their health practitioner colleagues and members of the rural communities. Equally, health disparities, vulnerable populations, economic dynamics and community resiliance were noted as was the rural nurses' pioneering spirit.

Discussion: The COVID-19 pandemic placed heightened demands on rural nurses and thus, potentially demanded changes in practice. Recognition has been given to compare whether the pioneering spirit associated with rural nursing practice, initially in the 1990s has continued in a similar vein, identified in the larger research project was evident during the COVID-19 pandemic. These findings have further lead us to reflect on lessons learnt from nurses' experiences and practice associated with the New Zealand 1918 flu pandemic.
\end{abstract}

\section{Keywords}

Rural nursing, COVID-19, Responsive models, Community, Change

\section{Introduction}

The context of this study stemmed from a larger research project $[1,2]$ to capture the stories of rural nurses' from rural Aotearoa, New Zealand. The aim was to shine light on these rural nurses' innovative practice. Rural nurses who practiced throughout the previous three decades in Aoteatoa, New Zealand were invited to share their rural story through narrative interviews. The previous three decades was of interest to the original researchers as this was a time of significant changing political health-care landscape and adapting provision of heath care including new models of nursing practice [1]. With the emergence of a new funding structure, the nursing landscape changed from a national to a local rural governance. As local governance developed, so did local responses - in particular rural nurses' responding to changing health needs and adapting their practice to accommodate this change. Their stories published in Stories of Nursing in Rural Aotearoa: $A$ Landscape of Care [1] illustrate their innovative responses to a variety of challenges. Many of the practices described in their stories have become national norms, celebrated as part of New Zealand's health story and if left untold, will be forgotten.

These rural nurses'stories show case a pioneering spirit and has helped us learn how nurses have adapted to the changing socio-political and economic rural environment which we can learn and reflect on. A parallel can be drawn between the COVID-19 pandemic 2020 and the provision of health care by nurses and the 1918 influenza pandemic. Historical events, literature and evidence [3-5] have prompted us to examine records and new narratives to determine how the nursing profession responded to past pandemics and the current 2020 pandemic. The goal of this research has been to

*Corresponding author: Jean Ross, Associate Professor Jean Ross, College of Health, Otago Polytechnic, Dunedin, New Zealand

Accepted: November 10, 2020

Published online: November 12, 2020

Citation: Ross J, Mann S, Leonard G (2020) Rural Nursing During the COVID-19 Pandemic: A Snapshot of Nurses' Experiences from Aotearoa New Zealand. J Nurs Pract 3(1):186-192 
establish how the COVID-19 pandemic has affected the practice of rural nurses from New Zealand.

\section{Background}

The rural population accounts for almost half of the total global population and these communities are confronted with reduced access and increased cost to healthcare, which contributes to increased health disparities. Rural people often suffer more than their urban counterparts as generally there is a reduced availability of healthcare providers and specialists [2]. Nurses make up the largest segment of the global healthcare profession and are in a critical position in reducing health disparities [2]. Given the global spread of the COVID-19 virus, which was determined to constitute a pandemic by the World Health Organisation on March $11^{\text {th }} 2020$, the complexity of this virus; how it is easily spread amongst the global population; its highly infectious nature and variety of symptoms it generates is well worth noting. The majority of people worldwide who become infected with this virus experience mild to moderate symptoms that include, a fever, sore throat, a dry cough, while more serve symptoms include shortness of breath [6]. Diagnosis of COVID-19 can occur anytime between 2-14 days from transmission. All members of the population can become infected. However, the most critical members of the population are, older people, those who have ongoing chronic respiratory conditions, while those who are immunocompromised while the indigenous populations of New Zealand and USA are also at higher risk of becoming severely ill.

Since the announcement of this global pandemic and in the months prior, the situation has developed in a nonlinear fashion. Moreover, not all regions of the globe have been affected in the same ways and to the same extent. Therefore, it is important to offer some information regarding the state of the pandemic from Aotearoa, New Zealand. We briefly discuss the state of affairs (around the time that the radio interviews were conducted to capture the experiences of rural nurses to shed light on their practice) between mid-March and late June 2020, as it applies to the COVID-19 pandemic and leads onto the methods of data collection and analysis informing the results and discussion later on in this paper.

\section{Aotearoa New Zealand}

The first confirmed case of COVID-19 in Aotearoa New Zealand occurred on the $28^{\text {th }}$ of February 2020. On March $4^{\text {th }}$, with six cases confirmed within the country, New Zealand's government announced that all those entering the country from anywhere other than the Pacific must self-isolate for 14 days. Fifteen days later, on March $19^{\text {th }}$, the New Zealand border closed to all but citizens and restrictions on gathering sizes were imposed. On $23^{\text {rd }}$ March, for the first time, certain cases within the country were treated as the result of community transmission. At midnight on March $25^{\text {th }} \mathrm{New}$ Zealand entered a state of emergency, or the most extreme lockdown "Alert Level 4" under the government's new Alert Level System, a move that had been premeditated and announced 48 hours earlier. The conditions at Alert Level 4 were said to constitute a "lock-down" of the country, as all but es- sential industries, along with travel and physical interaction, was prohibited. Alert Level 4 remained in place for five weeks, ending at 11:59 pm on April $27^{\text {th }}$. During this time, the number of active cases peaked to 929 cases ongoing as of that date. Nine days earlier, on March $29^{\text {th }}$, the first death from COVID-19 had been reported, with a woman in her 70s dying while receiving hospital care on the West Coast (shared by a rural nurse participant from this study who cared for her and presented in podcast 76). There have been 22 people (at the time of writing this paper) who have died within Aotearoa to date, the most recent occurring on May $28^{\text {th }}$.

As for medical practitioners, during Alert Level 4 medical clinics were instructed (by the Royal New Zealand College of General Practitioners) to reduce face-to-face appointments by 70 percent, in order to decrease social interaction whilst still providing a primary health care service [7]. Some in-person interactions that remained were significantly altered, such as flu vaccinations (responding to the winter seasonal change in New Zealand) being given to people through car windows in drive-in spaces. Similarly, hospitals ceased all non-essential services and policies restricting visitor access to those in hospital were implemented $[8,9]$. Fortunately, with case numbers contained by the nationwide lock-down, Aotearoa New Zealand's health system (nor any regional location) was not overwhelmed in the way seen in places such as northern Italy or Wuhan, China. As the thematic analysis below highlights, this is not to say that Alert Level 4 and the immediately preceding period were not pressing times for healthcare workers. Preparing the health system for increased community transmission placed a high demand on healthcare professionals in urban and rural centres. Moreover, the risks to healthcare workers became apparent. At the conclusion of Alert Level 4, one in ten of all those who had contracted COVID-19 in New Zealand were healthcare workers [10].

At Alert Level 3 (April $28^{\text {th }}$ - May $13^{\text {th }}$ ) the number of active cases continued to decline. Trade-related industries returned to operations and businesses such as restaurants and fast-food outlets could reopen and provide contactless delivery or pick-up services. Some on-site schooling capacity was reinstated in order to support the return of the workers to their worksites. However, schools remained closed. On May $4^{\text {th }}$ zero new COVID-19 cases were detected in New Zealand, a first since March $16^{\text {th }}$.

In the second half of May, new cases become infrequent and many were linked to already identified clusters. Aotearoa New Zealand went to Alert Level 2 on May $14^{\text {th }}$. The transition was staggered, with retailers reopening on the May $14^{\text {th }}$, schools reopening on the $18^{\text {th }}$ and bars and nightlife venues allowed to reopen on May $21^{\text {st }}$.

On June $8^{\text {th }}$ Aotearoa New Zealand's final COVID-19 case was deemed inactive, thus the country had no active cases for the first time since February $28^{\text {th }}$. At 11:59 pm the same day New Zealand moved to Alert Level 1, meaning almost all remaining restrictions on gathering and social interaction were lifted. However, the boarder remained closed to all but New Zealand citizens, and those who returned were required by law to enter government-run quarantine facilities for 14 days. 
At Alert Level 1 health services returned to normal operations (some planned care and elective procedures had started as early as Alert Level 3 and increased at Alert Level 2), with an increased emphasis on hygiene and infection control practices [11]. There has been a backlog of work needing to be done, and potential long-term health issues, considering the postponement of non-urgent services and decreased numbers of people accessing health services during Alert Level 4 [12].

\section{Method}

\section{Design}

This qualitative study is part of a larger research project, as described in the introduction. This part of the study referred to as a sub-project, has two research aims. The first aim was to capture the experiences of rural nurses from New Zealand during the COVID-19 pandemic and, in particular, to understand if/how this pandemic had affected the practice of these nurses'. The second aim was to compare whether the pioneering spirit has continued in a similar vein as to the changing socio-political and economic contexts in a time of significant change identified in the larger research project was evident during the COVID-19 pandemicin New Zealand and reflecting on lessons learnt from nurses' experiences and practice associated to the 1918 flu pandemic. In doing so we offer a summary of the analysis of nine interviews conducted with rural nurses in Aotearoa, New Zealand between late May 2020 and late June 2020. These interviews were conducted in order to record the experiences of rural nurses during the COVID-19 pandemic and, in particular, to understand if/how this pandemic had affected the practice of these nurses. By gaining an understanding the experiences and models of these nurses' practice highlights the dedication and skill of these rural nurses, during the COVID-19 pandemic; further informs existing theoretical knowledge and models of rural nursing practice, and serves as an impetus for further communication and collaboration between rural health practitioners, educational organisations and policy development in diverse international contexts.

\section{Ethics}

Ethical approval was originally obtained from the Otago Polytehnic Research Ethics Committee in 2017 to undertake the larger research project number 717. In May 2020 additional ethical permission was sought to further the research sub-project and request ongoing engagement with the rural nurses who consented to participate in the larger research project and for their stories to be published in Stories of Nursing in Rural Aotearoa: A Landscape of Care [1]. The Ethics Committee granted ongoing ethical approval as per the policy this request was granted as the original ethical application was less than three year old and the sub-project research project was able to progress.

\section{Participants}

Interview participants from Aotearoa, New Zealand were located through existing relationships with the first author. Nine participants agreed from the larger research project whose stories were published in Stories of Nursing in Ru- ral Aotearoa: A Landscape of Care [1] to participate in this sub-project. All of the original 16 rural nurses were contacted by email inviting them to contribute their experiences of practising in rural New Zealand during the COVID-19 pandemic.

\section{Data collection}

Data was collected from nine rural nurses (by the first author) as they contributed to semi-structured radio interviews, broadcasted in New Zealand. The overall intention was these interviews would be broadcasted on a local (in Dunedin, New Zealand) radio show, called Blowing Bubbles hosted by the second author and replayed as podcast numbers 46 and 66 . Blowing Bubbles is produced by Otago Access Radio with the support of Otago Polytechnic, both of Dunedin, Aotearoa/ New Zealand. The podcast consists of positive conversations with people from around the world (often from within their own "bubble") regarding their experiences of the COVID-19 pandemic and their views of the future in light of the pandemic.

With the permission of all the interviewees, audio recordings via zoom took place guided by the following questions, presented to each interviewee prior to the zoom meeting as follows:

- How you prepared for COVID-19?

- Has COVID-19 changed your practice?

- How your rural community has/is adapting to COVID-19?

- Have there been any challenges you have encountered?

- What does the future look like?

- Open the space for you to add additional thoughts.

\section{Data analysis}

The data from the interviews were digitally recorded (by the first author) and then transcribed (by the third author). As the bulk of material relating to the interview questions was present within the three episodes of Blowing Bubbles (podcasts 46 and 76) these episodes were analysed directly in order to thematically analyse the interviews themselves to understand the experience of these rural nurses through the COVID-19 pandemic. The origial audio recordings of each interview were edited (by the first and second authors) before being included in the podcast. The overal intention was to protect the identity of individuals (community members and health professionals) mentioned during the interviews. Material such as greetings between interviewer and interviewee was also removedin order to maintain the flow of the podcast. Nurses were offered being presented anonymously in the podcasts and this paper, but all chose to use their names.

\section{Results}

The following analysed sections have been separated for ease of presentation into Rural Nursing Practice and Rural Communities that compare, highlight and demonstrate the potential areas of continuity, change and ongoing development of the provision of healthcare by nurses in Aotearoa, New Zealand. 


\section{Rural nursing practice}

Communication and collaboration: The spread of the COVID-19 virus was rapid and unforeseen only months prior to it's becoming a pandemic. The speed at which the virus spread, and the exceptional state of affairs that this created, meant that a high degree of communication and collaboration was needed among health professionals, as well as between the health profession, political bodies and the public. Communication and collaboration were required in order to both exchange the most up-to-date information on the virus, as well as to organise health workers' and communities' responses. As the situation worsened, nurses and other health professionals from both Aotearoa, New Zealand began to meet with their rural colleagues on a more regular basis in order to keep abreast of the latest information and plan accordinglyas demonstrated in the following participant quotes first, from a New Zealand perspective as working closely or closer than pre COVID-19 with transdisciplinary teams leading to nurses as welfare providers discussed further in this paper, Very early on, probably in February [2020], we started seeing who could potentially be COVID patients... So, we kind of having a heighted sense early on in the piece before Ministry of Health and things really ramping up... at the end of February we activated our pandemic emergency management team... we needed to get some things in place pretty quickly. We started meeting on a twice-weekly basis... we set up isolation tents out the back of our practice... were probably two or three weeks ahead of the game (Rural Nurse, Hastie, podcast 46).

Communication and collaboration remained important as the situation developed. In the first instance, collaboration between health professionals was required in order to ensure adequate care for patients and adequate capacity should patient numbers escalate (an expectation). This often-involved nurses (and health workers more broadly) taking on responsibilities outside their normal duties as highlighted by the rural nurse participants who expressed that, [t] hank goodness I've been in this a long time because I had networks established. I don't think I could have done it quite so well without being able to phone a practice nurse or a GP and say "Hey l've just been speaking to, please can you do a script for me?"

\section{And}

... [no] man is an island and we all depend on one and other critically and without that we are really stuck... if you can't bounce on someone or debrief on someone or share your workload... and that became really critical too, was "Gee, I've got this patient coming, can you see them for this and then I can pick up and do what I need to do"... flexing out of our actual roles into other roles... (Rural Nurse, Hunt, podcast 46).

Communication with political bodies, such as local councils, and the general public was an important way of ensuring that all interested parties had the most up-to-date information and felt supported. Communication between nurses and members of the public is also important which is discussed further below in the "Nurses as Community Educators" section. Moreover, it was important to keep communication lines open between health workers and their employers. Health workers, both as members of the community and healthcare professionals responsible for the well-being of that community, needed to be kept up to date and supported in their roles.

Fear is an element of the nurses' narratives:

We very early on in the piece realised that patients weren't going to come see us... because of their own fear around contracting COVID in the practice. So, we activated a project called COVWELL, which basically is a COVID wellness... made these phone calls to all our high risks patients. This was about a 7 or 8 minute phone making sure they were well, that they understood, if they needed to go into isolation what that meant and what it looked like, making sure they had support around them... for them to know that actually you are on the end of a telephone if I do get sick...

(Rural Nurse, Hastie, podcast 46).

Nurses as welfare providers: It is evident from the commentary that the COVID-19 pandemic has affected the health and well-being of communities in ways beyond the contraction of the virus itself. The restrictions on movement and enforced social isolation, as examples, have caused stress and strain on individuals and communities. Broader community dynamics are discussed further below in the "Rural Communities" section. However, nurses often found themselves supporting community members and working in collaboration with other organisations through these challenges as demonstrated in the following excerpts from participant interviews,

...as soon we went into Level 4 we started working really, really closely with our [local authority] Council. I have to say building relationships at a time like this, and having good relationships in your community, is key

\section{(Rural Nurse, Hastie, podcast 46).}

For a lot of patients, it was reassurance in the first instance. For a lot of patients, it was the first call from a health professional to say "How are you? How are you doing? What's your bubble like? How are you managing? One old man I talked to hadn't been out for food for four weeks and was running out of food. So, I managed to get a food parcel dropped to him because he was frightened to come into town

(Rural Nurse, Hunt, podcast 46).

I saw one elderly man... he was like "I really need to go to the supermarket, but l just don't know"... so it was a phone call to [local authority] Council and by that afternoon his shopping was done for him. So, it's that kind of community buy in and communities working together, which I think you really have in rural communities... (Rural Nurse, Hastie, podcast 46).

It was also noted by one interviewee that the COVID-19 pandemic had provided an opportunity to put care back in the hands of patients themselves, where appropriate. This comment was made with regard to Ear Nose and Throat (ENT) health matters, rather than broader medical or pastoral care. However, it speaks to the larger issue of determining the circumstances in which a nurse is required, and for what purposes they are required.

It was nice to actually take a big deep breath and reflect 
on my practice... thinking about can we work smarter not harder... Maybe talking more with our patients and reassuring them that this is a progression of normal, rather than say "oh well, you better come in and see me". It's actually putting the power back to the patient, rather than us making the decisions for them (Rural Nurse, Hunt, podcast 46).

Nurses as community educators: As stated above, communication between nurses and members of the public was key in a context of rapidly changing information regarding COVID-19. In particular, nurses often acted as educators for the community; the first port of call for information on the virus as discussed by the following participants.

A lot of them [community members] were following on the news every night... they were asking us the questions, us as the first health professionals they were talking to... so we were the transmitters of up-to-date health information on a daily basis... we were the teachers about this disease process... and the encouragers

(Rural Nurse, Hunt, podcast 46).

...spending quite a lot of time educating the community about how to stay well, about how to recognise symptoms, what to do if they see symptoms... (Rural Nurse, Carter, podcast 46).

Practicing at a distance: The need for social distancing during the epidemic placed heightened importance on modes of care such as telemedicine and video-conferencing systems. The interviewees' commentary makes clear that there was sizeable variation in the extent to which different health providers were already utilising these technologies. The commentary also highlights that while COVID-19 has proved an opportune moment to embed these practices within care, there are inherent limitations to such methods as highlighted in the following excerpts,

[we] had already positioned the practice at the end of last year towards a more virtual, telehealth kind of ability to offer those services... as it turned out that facilitated us being able to work from home very easily... online video and telephone consultation worked really well. We had really high acceptance of that and, in fact, it's probably not something we'll want to let go... whilst it went really well, it's become very clear to us... there are certainly people you have to see... There is this core group of services that you can do no other way than by seeing people... it's certainly given us a level of comfort around the things we can do virtually... Where we can do them well and safely and conveniently then we should hold on to that and continue, and that's our plan

(Rural Nurse, Carter, podcast 46).

While Hastie expressed that;

...I'm part of the healthcare homes team... we've been trying to bring in teleconsultant and video consulting over the last 12 months and there's been a little bit of resistance to the change. And all of a sudden overnight we have no choice and it is here on our lap and how everyone has just adapted and accommodated that change and got on with it...we're still doing telephone consults; we're trying to really ramp up on video consultations. So, the way we deliver care, it's a really good opportunity for us to embed some of that practice that we've changed during COVID (Rural Nurse, Hastie, New Zealand, podcast 46).

Upskilling or acquiring new knowledge on the job: As a result of health workers needing to be willing to step outside of their regular duties during these exceptional circumstances, upskilling and rapid on-the-job learning was required, through research in the literature, depending on colleagues knowledge, and revisiting whether practise techniques are valid and sharing that information together,

What are we going to need to do around the practice environment to make it safe for us and to make it safe for patients to access... what are the implications for healthcare workers that may be exposed... there was a lot to work through... you can't do a lot of that ahead of time. It is often very specific to the nature of the crisis you are about to face... using the clinical evidence from overseas... using that in our planning to think about the information and advice we were going to give patients...

(Rural Nurse, Carter, podcast 46).

It's definitely changed our practice. I think it's made us more aware of infection control procedures, you know, everything, we've just had a massive overhaul in everything we kind of do, right down to our cleaning... it's just made us revisit a lot of things we probably haven't visited in a long time (Rural Nurse, Hastie, podcast 46).

...we had three nurses on every shift and my role became very much a coordinator in the unit... my primary goal was to try and make nurses comfortable with what they were doing and what the patients could potentially be like. A lot of my colleagues I was working with were surgically based nurses, not medically based nurses, so respiratory illness was something they were challenged by...

(Rural Nurse, Pollard, podcast 76).

Rural Communities: In many ways some of the following comments on rural communities' responses to the COVID-19 pandemic could be included in the preceding "Rural Nursing Practice" section, as the commentary makes clear that rural nursing practice cannot be separated from the rural communities that rural nurses operate within. For example, the close-knit nature of many rural communities plays a large part in requiring rural nurses to act as role models in their daily interactions. However, this section also touches on the general characteristics of rural communities and how those communities have worked to confront the challenges posed by COVID-19.

Healthcare disparities and vulnerable populations: Interviewees highlighted that the COVID-19 pandemic, and resultant restrictions, did not affect all community members equally. Certain demographics within communities were at higher risk from COVID-19 due to, their physiological profile (e.g. age) and socio-economic status. Communities with elderly populations stood to be heavily affected by the pandemic if widespread community transmission were to occur, 
...probably a quarter to a third of our practice population are over the age of 65... we have one of the highest rates of over-80s remaining at home with support [in NZ]... think about that population... we [also] have a workforce that is often older... (Rural Nurse, Carter, podcast 46).

Moreover, lower socio-economic demographics were less likely to present for healthcare at an early stage of being unwell, due to historic and ongoing inequalities in access to healthcare.

Economic dynamics and consequences: The following interview highlights the broader economic impact that was already being seen within rural communities as a result of the COVID-19 epidemic.

As for our community, it's really grim. There's something like $60 \%$ unemployment in hospitality and tourism. So, those people are here not working and trying to survive... we're starting to see a lot of mental health issues and financial strain... there's quite a lot of drug use we're seeing coming through...(Rural Nurse, Hastie, podcast 46).

Community resilience, working and supporting each other: Despite these hardships, the interview commentary highlights that rural communities are resilient and that much of this resilience comes from close-knit relationships of support. Community members support each other and their healthcare workers. There is a sense that the COVID-19 pandemic has strengthened understanding and kindness towards others, as well as appreciation for one's lot. The following participants' excerpts reflect on the community resilience.

This pandemic is just one in a string of fairly regular issues... a few months ago we had massive flooding... I think it just is another example that rural communities are quite resilient... whether it's a pandemic or a flood, what we see in rural communities is that we can rely on each other... I wasn't expecting anything less it is always, though, affirming... when you see it again (Rural Nurse, Carter, podcast 46).

We're very kind to each other now, staff-wise, patient-wise, we just give each other a little bit more leeway - "Gee, you've been really busy with COVID. You must be tired", you know? We're just a little more thoughtful towards each other (Rural Nurse, Hunt, podcast 46).

Appreciation from the people in your community...just people seeing you in the supermarket going "thank you" ... it has been a really, really, humbling experiencing (Rural Nurse, Hastie,podcast 46).

Our tourists have gone, is the reality, and we are now back to community... things are not great here in our community. We have phenomenal unemployment. We have redundancies left, right and centre but at the heart of it are those people who truly love this community... and that has been really nice because we rally around each other... so it's definitely brought back the heart of our local community (Rural Nurse, Hastie,podcast 46).

... we're very dedicated to each other. People reach out to each other very much and the connection that people make is just incredible... I would say thank you to the West Coast for being open, for reaching out and for being incredibly patient... (Rural Nurse, Pollard, podcast 76).

...events like this really call into question for people what is fundamentally the most valuable and most important to them and I think we've seen a real slow-down... an actual slow-down in the way people are approaching their lives... I'm seeing and I'm feeling a lot less consumerism. I'm feeling a lot more that people are appreciating what they have... long may that last. (Rural Nurse, Carter, podcast 46).

In the main, the community wrapped itself around any identified older people (Rural Nurse, Hunt, podcast 46).

Yet, there can be no doubt that rural communities have been deeply affected by the epidemic.

In searching for positives to come from the COVID-19 epidemic, a common theme (along with the increased kindness and engagement with disadvantaged communities mentioned above) was that health literacy and general wellness within the overall population may well increase,

...certainly, the hand washing has paid dividends. All my patients have come back, there are no colds in any of my children. There are no coughs, there's no flu-like symptoms... (Rural Nurse, Hunt, podcast 46)/

\section{Discussion}

In the larger research project [1], nurses described the role of innovative practices in their professional framework of practice. For example, Neta Smith [1] (p.21), describes "the expectation I have on myself is to deliver the best service that I can for our community" and to do that she had to "go for gold". Similarly, Marg Hunt [1] (p.23) expresses that "it makes you think outside the square...question, and question and question, and not take no for an answer". In the face of the pandemic, it is interesting to consider whether how the characteristics of this pioneering aspects of practice have prepared these rural nurses for the responsive, leadership and change agent roles expected of rural nurses during this COVID-19 pandemic.

To some extent it is in the nature of rural nursing practice that models are developed on the edge - almost all the stories in Ross and Crawley [1] can be considered as voices from the edges, both in terms of geography and practice, whether it be establishing nurse-led health practice on an isolated island or working to keep minor surgery in a rural area. So, in the COVID-19 pandemic, most of the practices in the small - using Personal Protective Equipment (PPE), caring for people with specific needs - are things in the toolkit of the rural nurse. There are some new skills - telemedicine and so on - but it is in the large where practice has really been challenged. Perhaps it is the scale of the pandemic and the speed and degree of disruption, combined with the challenges specific to place that leads to new challenges - setting up new triage systems overnight, moving into new practice areas, strengthening infection control and so on. But perhaps rather than "new" these are also the old challenges, what we have seen is the practice of rural nursing working as it should. Whether the rural nurse be role models in the community, taking responsi- 
bility for community messaging, establishing systems for supporting vulnerable populations, or acquiring new knowledge as circumstances change - these are all characteristics of the practitioner operating at "the heart of the rural community".

We have heard the word "unprecedented" a lot in New Zealand during the pandemic, and indeed in these discussions with rural nurses. It is, of course, not unprecedented, the flu pandemic of 1918 was worse in terms of effects on rural communities in New Zealand. Rice [3] describes how in 1918 hospitals and medical personnel were quickly overwhelmed. It was a "terrible time", especially for rural nurses "I was sent North, my family never expected to see me again" [3] (p.62), "I rode [on horse-back] forty-odd miles daily, there were so many side tracks. One home I went to, a father, mother and small boy were down, the boy obviously dying so I gave him all I could and had to leave him. Next morning, he had died". Fortunately, we have not reached the dire straits of 1918, possibly because of the very lessons learnt in the years after 1918 - the establishment of the public health system in New Zealand, the recognition of the role of rural nursing [4] and the need for a wide understanding of the skills needed (and how this changes, perhaps the horse of 1918 is now telemedicine in 2020). Rice [3] argues that the New Zealand influenza pandemic plan which sets out a whole of government reaction which formed the basis of the 2020 response "embodies the lessons from 1918". It is our contention that if we do not take the opportunity to learn from the 2020 pandemic, the next major disruption (pandemic) will also be considered unprecedented.

It is crucial that nursing education and policy development be examined to establish if any changes need to be made following the COVID-19 pandemic. This should form the basis of further research and it is vital that this includes the voices of rural nurses.

\section{Limitations}

This research was conducted during New Zealand COVID-19 lockdown when a small number of rural nurses were invited to contribute. These rural nurses were a convenient smaller sample of the original rural nurses' research project who had originally agreed and consented to contribute to the larger research process limiting the significance of the results.

\section{Acknowledgments}

The authors wish to thank the rural nurses who gave up their valuable time to share their valuable stories and experiences and agree for these to be broadcasted on radio. The authors also wish to acknowledge their bravery and dedication to continue to offer the members of their rural communities an adaptable and changing health care delivery, during an unprecedented time. The authors would also like to thank Otago Access Radio with the support of Otago Polytechnic, both of Dunedin, Aotearoa, New Zealand to proadcast these podcasts.

\section{Conflict of Interest}

The authors declare they have no conflicts of interest.

\section{References}

1. Ross J, Crawley J (2018) Stories of nursing in rural Aotearoa: A landscape of care. $\left(1^{\text {st }}\right.$ edn) Rural Health Opportunities, Dunedin, New Zealand.

2. Ross J, Crawley J (2019) Narrative inquiry insights: Rural nurses responses to decades of change. Scope Contemporary Research Topics, Health \& Wellbeing 4: 63-72.

3. Rice $G$ (2018) That terrible time: Eyewitness accounts of the 1918 influenza pandemic in New Zealand. Hawthorne, Christchurch, New Zealand.

4. Roddick JA (2005) When the flag flew at half-mast. Masters Thesis, School of Nursing, Otago Polytechnic, Dunedin, New Zealand.

5. Wood P (2020) Overworked and overwhelmed: How NZ nurses coped with the 1918 pandemic. Stuff.

6. World Health Organization (2020) Coronavirus.

7. Hills T (2020) How to see your GP in lockdown New Zealand. And what you can do to help us. The Spinoff.

8. Martin H (2020) Coronavirus: Hospitals ban visitors under lockdown. Stuff.

9. Quinn R (2020) COVID-19 coronavirus: Up to 30,000 surgeries called off during lockdown. Herald.

10. Martin H (2020) Coronavirus: Healthcare workers make up 1 in 10 of New Zealand's COVID-19 cases. Stuff.

11. Ministry of Health (2020) Health and disability services at Alert Level 1.

12. Newton N, Espiner G (2020) COVID-19 coronavirus: Delayed hospital treatment could cause deaths, post-lockdown 'mess'. New Zealand Herald.

DOI: $10.36959 / 545 / 382$

Copyright: (C) 2020 Ross J, et al. This is an open-access article distributed under the terms of the Creative Commons Attribution License, which permits unrestricted use, distribution, and reproduction in any medium, provided the original author and source are credited. 